\title{
Favelei: Antropofagia e hibridação no caso da funkeira MC Véia
}

\section{Favelei: Anthropophagy and hybridization in the case of the funk of Mc Véia}

\section{Míriam Cristina Carlos Silva}

Universidade de Sorocaba (UNISO). Mestrado em Comunicação e Cultura.

Doutora em Comunicação e Semiótica. Professora no Mestrado em Comunicação e Cultura e líder do NAMI (Grupo de Pesquisa em Narrativas Midiáticas), na Universidade de Sorocaba. Desenvolve projeto de pesquisa em Narrativas Midiáticas, apoiado pela Fapesp

\section{Thífani Postali}

Universidade de Sorocaba (UNISO).

Mestre em Comunicação e Cultura, pesquisadora do MidCid (Grupo de Pesquisa em Mídia, Cidade e Práticas Socioculturais) e professora da Universidade de Sorocaba. Publicou "Blues e Hip Hop: uma perspectiva folkcomunicacional" e "Cidade e Comunicação: a miopia sobre o mundo e outros textos"

Resumo: Este artigo discute o fenômeno midiático "MC Véia”, que se transformou a partir do funk carioca. Utilizamos conceitos que revelam os processos de antropofagia, com Oswald de Andrade, e hibridação cultural, com Néstor Canclini. Martín-Barbero e Herschmann são fundamentais para a discussão sobre identidade híbrida. Leda Maria Soares Ferreira, a "MC Véia", teve uma história de vida marcada por perdas de afeto e de identidade. Do medo à inserção, aceitação e incorporação da diferença, MC Véia mescla identidades, gerando referências inusitadas ou híbridas, e declara ter se "favelado". Como metodologia, utilizamos a pesquisa bibliográfica e exploratória, a avaliação de matérias em revistas e sites, entrevistas cedidas por Leda Maria à mídia e análise da página de MC Véia no Facebook.

Palavras-chave: comunicação e cultura, antropofagia, funk.

Abstract: This article discusses the media phenomenon "MC Veia", which has modified herself because of the "carioca funk". We use concepts that reveal the processes of anthropophagy, by Oswald de Andrade, and cultural hybridization, with Néstor Canclini. Martin-Barbero and Herschmann are fundamental to the discussion of hybrid identity. Leda Maria Soares Ferreira, "MC Véia", had a history of life marked by loss of affection and identity. From her initial fear to the insertion, acceptance and incorporation of difference, $M C$ Véia merges identities, generating unusual or hybrid references, and she declares to have "favelado" herself (adopting a slum living style). The methodology used was the bibliographic and exploratory research, the evaluation of articles in journals, sites and interviews Leda Maria has ceded to press and also the analysis of MC Véia's Facebook page.

Keywords: communication and culture, anthropophagy, funk. 


\section{Do funky aos funks}

Para Herschmann (2000), um dos grandes desafios dos pesquisadores contemporâneos, é perceber, nas expressôes culturais marginalizadas, algo além das sensaçôes de desordem e de caos, causadas, especialmente, quando os meios de comunicação de massa procuram retratar algumas manifestações populares de maneira negativa e / ou restritiva.

O funk brasileiro ou funk carioca, como é conhecido no Brasil, está entre as expressôes populares mais evidenciadas nos últimos três anos, por ter alcançado a visibilidade dos principais veículos de comunicação brasileiros, mas a sua história não é recente e evolve severas críticas, vindas de distintos segmentos da sociedade, sobretudo quanto ao seu conteúdo.

É fato que a expressão musical ganhou uma configuração singularmente brasileira, mas sua origem está atrelada ao ritmo estadunidense soul que, segundo Herschmann (2000), trata-se da união entre os ritmos gospel e rhythm and blues que em meados dos anos de 1960, ganhou mercado e visibilidade mundial a partir de nomes como Ray Charles e James Brown. O termo funky surgiu no final da década de 1960, decorrente de um sentimento de alegria e de "orgulho negro" (HERSCHMANN, 2000), passando a significar uma vertente da música ainda capaz de produzir uma sonoridade que representasse a negritude. Citando Hermano Vianna, Herschmann acrescenta que, a partir desse momento, todos os elementos que representassem os afrodescendentes, poderiam ser chamados de funky. Ou seja, a palavra passou a determinar as características de um grupo social, como roupa, gírias, jeito de andar, dançar e, até mesmo, o bairro - local que acomoda tais elementos. A música, que dava ritmo àquele momento, ficou conhecida como Funk.

Cabe salientar que, nesse período também surgiu um ritmo derivado do rhythm and blues, portanto, similar ao funky. A música do Hip Hop ${ }^{1}$ possuía a mesma base, entretanto, como coloca o autor, utilizava uma composição com sons mais pesados e arrastados. É importante ressaltar que a manifestação cultural Hip Hop tem como objetivo principal discursar sobre os problemas sociais que afligem as camadas que ocupam as favelas e os subúrbios das cidades.

Talvez o Hip Hop tenha se diferenciado do Funk pela influência dos ritmos jamaicanos ${ }^{2}$, quando parte da populaçáo jamaicana mudou-se para os guetos nova-iorquinos em busca de melhoria nas condiçóes de vida. Falamos brevemente do Hip Hop, pois as duas manifestaçóes culturais, muitas vezes, são confundidas. Ao contrário do Hip Hop, o Funky desenvolveu um ritmo mais alegre e contagiante, descompromissado quanto ao cunho crítico-social. Desta forma, projetou-se internacionalmente, dando início ao modismo "disco" praticado em diversas regióes do mundo, inclusive no Brasil.

Em 1970, a casa de shows Canecão, uma das mais famosas da cidade do Rio de Janeiro, promoveu os chamados "Bailes da Pesada". Nesses eventos, Djs como Big Boy e Ademir Lemos discotecavam ritmos como rock e pop. De acordo com Herschmann (2000), os Djs passaram a dar maior destaque aos músicos de soul como James Brown, Wilson Pickett and Kool and the Gang, dando início à cultura Funky carioca. Mesmo com os eventos atraindo cerca de 
5 mil jovens, a administração do Canecão passou a investir na MPB, fazendo com que os Bailes da Pesada fossem transferidos para outras regióes da cidade.

No Brasil, o Funky não comportou a mesma ideologia que os grupos estadunidenses. De acordo com Herschmann (2000), poucos bailes promoviam o formato militante sobre o "orgulho negro". Isso porque o estilo discotecagem agradava tanto aos jovens da zona Sul quanto aos da zona Norte da cidade. Outro fator que inibiu esse viés foi a repressão implementada pelo regime militar, principalmente relacionada às produçôes culturais.

Em 1980, a zona Sul passou a valorizar o rock nacional, deixando a discotecagem de lado. Todavia, a zona Norte continuou a reproduzir a música negra estadunidense, importando os novos ritmos de funky. A maior produtora e promotora de shows, a Furacáo 2000, começou a realizar bailes no subúrbio do Rio de Janeiro e, a partir desses eventos, as práticas importadas começaram a incorporar elementos locais, criando uma nova forma de produzir e vivenciar o estilo musical. De acordo com Herschmann (2000), as danças passaram a ser grupais, e o ritmo também se distanciou do soul.

Com relação a essa fusão, cabe apresentar o conceito de hibridação, de Canclini (2008), traduzido como a união de estruturas ou práticas sociais discretas, que acabam por gerar novas manifestaçóes culturais. Para o autor, "isso ocorre de modo não planejado ou é resultado imprevisto de processos migratórios, turísticos e de intercâmbio econômico ou comunicacional. Mas frequentemente a hibridação surge da criatividade individual e coletiva" (p. 22).

Cabe ressaltar o fato de que, na década de 20, Oswald de Andrade formularia o conceito de antropofagia, o qual comporta um diagnóstico e um prognóstico da cultura, das artes e, se compreendido em profundidade, do modo de ser do brasileiro. Ao mesmo tempo em que prevê a retomada das origens, mas de modo crítico, aprendendo com o índio e o negro, não os mitificando, também propóe a crítica antes da incorporação do que nos chega de fora. Há a valorização da técnica, somada ao primitivo. $\mathrm{O}$ que se destaca aqui é a possibilidade de uma leitura, da cultura e de seus produtos, relacionados às mídias, que continua atual e necessária. Uma proposta antropofágica de compreensão dos fenômenos, que: "Expressaria o desejo de descolonizar a cultura, a busca de um ponto de vista descentrado que corresponderia, ao mesmo tempo, a uma renovação estética e ideológica” (FIGUEIREDO, 1995, p. 85).

A antropofagia, portanto, prevê a seleção e digestão das referências alheias, para transformá-las, em um processo não apenas crítico, mas sobretudo autocrítico. Trata-se de um exercício de alteridade, pois para se devorar o alheio é necessário, antes de tudo, deixar-se devorar. Não há antropofagia no simples convívio ou na tolerância entre os diferentes. $\mathrm{O}$ antropófago processa o alheio, transformando-se em outro, um híbrido, para se fazer a ponte com Canclini. E este híbrido conta, por exemplo, com a linguagem popular, desestabilizando a erudição como um lugar privilegiado de fala: 
Através deste movimento estratégico, limita-se o lugar do homem culto, estabelecido e garantido, ao usuário daquela retórica, como a possibilidade de exclusão, de estar acima do comum e assim garantir seu privilégio no espaço da sociedade dos desiguais (SEPÚLVEDA, 1995, p. 13)

\section{Reforçamos com Bueno:}

Oswald de Andrade, a moderna cultura antropofágica brasileira, e seus criadores, jamais propuseram, ou aceitaram, rígidas distinçôes entre cultura de elite, cultura de massa e cultura popular, sendo traço central do projeto o livre trânsito entre tais níveis de criação cultural (BUENO, 1995, p. 64).

Deste modo, o funky importado, que já nasce como uma mescla de referências anteriores, em uma tendência antropofágica, foi se transformando ainda mais junto à cultura local e, a princípio, tornou-se conhecido a partir das expressôes "funk", "balanço" e "funk pesado" (HERSCHMANN, 2000). A medida em que o funk se abrasileirava, também se distanciava cada vez mais de grupos militantes cujas propostas eram firmar o "orgulho negro" ou resistir frente ao sistema social dominante. Isso porque, esses grupos acusavam os funkeiros de produzir músicas descompromissadas com o grupo social, dedicando-se apenas ao entretenimento.

Com relação à cultura popular, cabe-nos ressaltar sua capacidade de ser híbrida, ou seja, antropofágica, por ser livre, indomável, maleável, informal e transitória, avessa a autoritarismos e segmentaçóes fechadas, já que nela se configuram, em amálgama, combinaçóes das representaçóes do cotidiano, da memória, da tradição, somadas às manifestações hegemônicas, formalizadas pelas instituições e pelas mídias. E em nossa leitura de Martín-Barbero, por sua capacidade de representar segmentos sociais sem voz, por construir, não sem conflitos e tampouco sem incômodos, nas tensóes, visibilidades:

$\mathrm{O}$ valor do popular não reside na sua autenticidade ou na sua beleza, senão na sua representatividade sociocultural, em sua capacidade de expressar o modo de viver e pensar as classes subalternas as maneiras como sobrevivem e as estratégias através das quais filtram, reorganizam o que vem da cultura hegemônica, e o que integram e fundem com o que vem da sua memória histórica (1997, p. 55).

Em 1989, ocorreram as primeiras gravaçôes do funk nacional, com letras cantadas em português. De acordo com Herschmann (2000), o DJ Marlboro produziu o disco "Funk Brasil no 1", que marcou o início do funk carioca.

A partir dos anos 1990, o funk ganhou visibilidade através dos veículos de comunicação de massa. Todavia, o recorte feito pela mídia apresentava uma música associada à criminalidade e ao sexo praticados nos bailes das favelas cariocas. Não nos cabe apresentar o funk como dissociado dessas práticas, porém, é importante lembrar que a mídia constitui "um dos principais cenários do debate contemporâneo; é através dela, de modo geral, que se adquire visibilidade e que se constroem os sentidos de grande parte das práticas culturais" (HERSCHMANN, 2000, p. 88). Como grande mediadora das narrativas do cotidiano, a mídia pode incitar, portanto, à reflexão, à crítica e à identificação, 
bem como naturalizar clichês e preconceitos.

Deste modo, a musicalidade criou uma identidade relacionada a sexo e, principalmente à violência dos jovens favelados. Herschmann apresenta um estudo sobre as matérias publicadas nos principais veículos de comunicação, na primeira metade da década de 1990. Na ocasião, sustenta que o funk compôs os títulos das matérias relacionadas à violência, como exemplo: "Galeras do funk criaram pânico nas praias"; "Movimento funk leva à desesperança" (2000, p. 96). É certo que a manifestação foi assimilada à quantidade de ocorrências de violência praticadas nos bailes, somadas aos índices de criminalidade dos jovens e pesquisas de opiniấo que fundamentavam essa identidade. Mesmo que existissem outras formas de produzir o funk, o destaque se deu nas produçóes que estavam em evidência.

MC Garden, a exemplo, faz parte de uma vertente chamada "funk consciente" ou "funk de protesto" que, assim como o Hip Hop, procura chamar a atenção para os problemas sociais que afligem os jovens e a sociedade brasileira. MC Garden ganhou notoriedade no ano de 2013, através das redes sociais, num momento em que os jovens foram às ruas nas chamadas "Jornadas de junho", protestar contra o sistema econômico e político brasileiro. Todavia, essa vertente não ingressou na mídia, que deu espaço a outra forma intitulada "funk de ostentação". Apresentado em 2012, o "funk de ostentação" procura inserir em suas letras, além da sexualidade, assuntos que dialogam com as classes mais abastadas, como marcas de grifes, carros importados, dinheiro, baladas, bebidas destiladas e poder. Criado no estado de São Paulo, esse funk passou a ser articulado pela mídia, alcançando as trilhas sonoras de novelas, propagandas publicitárias e bailes realizados em todas as classes sociais. Para justificar essa inserção, podemos nos apoiar em Herschmann para quem "a mesma mídia que demoniza é aquela que abre espaços nos jornais e programas de televisão". Para o autor,

A produção jornalística implica diversos modos específicos de se ver e relatar o "real", os quais diferem de um veículo para outro (ou mesmo variam dentro de um mesmo veículo), o que pode resultar na construção de diferentes significados para os acontecimentos dentro da mídia, tendo assim em conta apenas as múltiplas possibilidades de suas construçóes discursivas. Ou seja, os elementos são formados por elementos também exteriores a ele, e em grande medida condicionados pelo sujeito que vai reconhecê-los, relatá-los, construí-los (2000, p. 89).

Entretanto, é possível perceber a reprovação dessa vertente por parte destes jovens das favelas e subúrbios. Isso se dá, talvez, pelo fato de ele ter deixado de dialogar com estes grupos, passando a incorporar atitudes, objetos e situaçóes distantes de sua realidade social. Neste sentido, cabe questionar o papel da mídia no diálogo e na representação da diversidade e da alteridade. Enquanto a vertente ostentação ganhava visibilidade midiática, por um lado, reforçava os estereótipos e estigmas da violência passíveis de crítica, somando, a estes últimos, os do consumismo inconsequente, o status pelo ter, não pelo ser. Por outro lado, esta mesma mídia produzia ainda mais assimetrias entre os grupos, já que emudecia e fazia invisíveis as vozes destoantes (ainda que minoritárias 
e, na gênese, associadas ao movimento Hip Hop), que questionavam sobre as desigualdades e pediam por mais justiça social, em consonância com os protestos de 2013, bem como daqueles jovens comuns, que não encontravam mais identificação nem com a mídia, distante de seu cotidiano, tampouco com o funk ostentação, que não os representava mais.

Em 21 de agosto de 2014, a revista CartaCapital publicou uma matéria intitulada "Ostentação em crise", explicando que a decadência da vertente não se deve só ao fato de não dialogar com o grupo social de sua origem, mas também por seus produtores bloquearem a disseminação das músicas e vídeos na internet.

Outras vertentes que devem ser consideradas é o "Proibidáo" e "Funk Putaria”. A primeira retrata a criminalidade ocorrida nas favelas - semelhante ao Gangsta Rap, muitas dessas músicas fazendo apologia ao crime, consumo de drogas e até, relatando açôes reais de facçôes criminosas. Essas produções são comercializadas de forma clandestina. Já as letras da segunda retratam a pornografia. As produçóes podem ser encontradas em rádios on-line como a Radio Funk Brasil, disponível em http://www.radiofunkbrasil.com.br/.

\section{Mc Véia}

O funk sempre esteve associado aos jovens, com letras consideradas muitas vezes machistas e pornográficas. As produçóes femininas ganharam projeção a partir de 1995, com a funkeira Tati Quebra-Barraco, que em suas letras aborda o sexo e faz uso de palavróes. Porém, o funk feminino cresceu nos últimos anos, com uma leva de garotas inspiradas em nomes da cultura pop estadunidense. De acordo com matéria publicada no site G1 (www.globo. com) MC Beyoncé, MC Britney e MC Rianna são alguns nomes escolhidos para homenagear e para ajudar a conquistar a popularidade. Geralmente, suas letras procuram falar de relacionamentos, exaltar a mulher com atitude, que briga e ostenta os bens materiais. Cabe lembrar que as qualidades exaltadas são aquelas valorizadas dentro do grupo social no qual estão inseridas.

Leda Maria Soares Ferreira, a MC Véia, nasceu em Mutum, interior de Minas Gerais. Mudou-se com a família para o Rio de Janeiro aos 14 anos, vivendo em Copacabana até os 23 anos de idade, quando se casou com um militar. Mudou-se para o Bangu, na zona Oeste da cidade, onde era professora de maternal.

Em entrevista para a Folha de são Paulo (2014), Leda Maria conta que separou-se do marido e, no ano de 2000, foi morar no bairro de Cosmos, considerado um local violento e marcado pela pobreza. A senhora de 67 anos, ainda lembra que, no início, ficava apavorada com os vizinhos que tocavam funk a um som muito alto.

Em uma matéria publicada no G1 (globo.com), Carol Marques conta que Leda Maria é bastante diferente do perfil da maioria dos jovens de funk que utilizam gírias comuns ao grupo. Assim, no bairro de Cosmos entrou em contato com os modos de vida local, passando a incorporar certas práticas. Em sua página do Facebook ${ }^{3}$, a funkeira utiliza uma linguagem voltada ao 
público como a frase publicada em 16 de setembro de 2014: "Bom dia, meus novinhos!!! Daqui a pouco Mc Véia voando pra cidade que nunca para! Sampa, se segura, que eu tô chegando!" Cabe ressaltar que o termo "novinha” é bastante utilizado por funkeiros cariocas e paulistas, principalmente em letras que remetem ao funk Ostentação e Putaria. A funkeira explica que se acostumou com o ambiente agitado e com o ritmo do funk, passando então a criar letras que retratam suas experiências de vida. Sua primeira canção, "Concubina", discorre sobre uma traição, seguindo o perfil do funk feminino: "Escuta o conselho da véia/ te cuida, se pinta / você é tão bonita / Cuidado com o ataque da concubina / ela é bonita, cheirosa / e sabe que é gostosa / se você não se cuidar / vai perder pra concubina / mostra o teu corpão / e beija o teu machão e diz / morro, morro, morro de paixão [...]".

Outro ponto a se destacar é o uso que Leda Maria faz da rede social Facebook para também incitar a interação do público. Referindo-se à música "Concubina", a funkeira publicou no dia 2 de setembro de 2014 a frase "Marque aqui sua amiga que precisa tomar cuidado com o ataque da CONCUBINA!”.

Atualmente, o termo híbrido, abordado por Canclini, propóe o encontro entre culturas, partindo da ideia de que são "processos socioculturais nos quais estruturas ou práticas discretas, que existiam de forma separada, se combinam para gerar novas estruturas, objetos e práticas" (2008, p. 19). Também a ideia de antropofagia, antecipada na década de 20 por Oswald de Andrade, pode auxiliar em uma leitura mais complexa do fenômeno, ainda que em contextos espaciais e temporais distintos:

É na brusca mudança da sociedade paulista, provinciana, transformada em industrial, na estética do "choque", que os modernistas de 1922 fundam seu imaginário, ou melhor, enraízam suas representaçôes estéticas. E, por brutal e violenta, a ruptura dos modos de vida, no quadro de uma cultura urbana, não consegue se expressar senão em um discurso fragmentário desestruturante, enfim, uma retórica que "esconde" os seus referentes, já que não os pressupóem, antes, pelo contrário, é por eles pressuposta (SEPÚLVEDA, 1995, p. 13).

Com a produção de sua literatura antropofágica, fragmentada, composta de amálgamas entre a cultura erudita, a popular e a de massa, o que Oswald de Andrade denuncia, segundo Sepúlveda, é "a insuficiência daquela literatura "nobre", apenas possível dentro de uma estrutura social esquemática, engendrada numa comunidade de lugares previstos, imóvel” (1995, p. 14). Cunha expóe que: "Para Oswald, a antropofagia é a diferença a ser ressaltada, reassimilada e afirmada, como valor não de traço de origem, e sim de emergência de uma regra de assimilação a ser invertida” (1995, p. 54).

Contemporaneamente, o funk se dá também em um contexto de múltiplas rupturas, em que o crescimento desordenado dos grandes centros, somado à precariedade das políticas públicas, caminha com o aumento da violência, a oferta variada de bens de consumo e o desencanto diante da falta de perspectivas em todas as instâncias sociais. Paradoxal, o funk pode ser lido como manifestação que emerge do Hip Hop das periferias, do protesto, da angústia 
materializada em grito de agressão vindo do agredido, para convergir no louvor ao consumo, ao prazer e desembocar nas mídias. É fruto da imprevisibilidade e da incerteza, colocando em questão a ideia de cultura (e de gosto) musical.

Também a história da construção midiática de MC Véia vem de uma brusca ruptura social, a qual pode ser vista como um processo de hibridação cultural, ou de antropofagia. Ela própria criou uma música explicando suas relações com o outro grupo social: "Favelei" narra a inserção no funk e na cultura da favela:

Dei de cara na favela com a turma do Pancadão/ eu me assustei/ eu me assustei./ De tanto ouvir o funk/ confesso me amarrei/ Sem caô, eu favelei/. Gente tão bacana/ que até divide o pão/ Becos e vielas, sempre tem um amigão/ Eu me amarrei e favelei. [...]. Bacana, aí você se engana/ o favelado é gente boa pra caraca (...).

Leda Maria, ao relatar sua experiência nas letras dos funks que compóe, bem como ao ser retratada pelas mídias, transforma-se em narrativa, na qual é narradora e também personagem. Opera-se uma passagem: a dos fatos do cotidiano para o plano simbólico, o da realidade interpretada. Leda Maria compóe-se entáo de inúmeras camadas: a narradora e a personagem, as quais conjugam a mulher de classe média, professora, bem-educada, casada com militar, mas também a esposa abandonada, marcada pelo insucesso financeiro e que necessita deixar (por duas vezes) o seu lugar de origem para adentrar a outra cultura: de Minas a Copacabana e, depois, ao subúrbio carioca. Todas estas camadas são colocadas, antropofagicamente, em diálogo, não sem tensôes e conflitos, mostrados em "Favelei", quando se destaca a favela como antagonista, representante da diferença, estigmatizada e que, por ser estranha, provoca medo. Mas o contato é inevitável e, com ele, a contaminação, a hibridação. Ao olhar para o diferente, a favela mostra-se para Leda além do estigma. Da visão antes indireta, passa-se à experiência vivenciada com o próprio corpo, direta, mídia primária, na qual se materializam as sensaçóes, sentidos e as memórias, a cultura, portanto.

De antagonista, a favela passa a adjuvante, compondo-se uma nova narrativa, na qual se destacam os laços de solidariedade e do compartilhar. O movimento de abertura para a diferença dá lugar a outra leitura, mais complexa, e à possibilidade de uma nova ação, a de "favelar-se".

MC Véia permanece com traços do estrangeiro, por ser uma senhora, idosa, em um universo jovem. Esse estranhamento chama a atenção e a transforma em um valor-notícia para as mídias, por seu componente de inusitado e pelo quê de caricatura e humor que representam a atuação da funkeira idosa, que não é completamente funkeira, mas também que já não pode mais ser considerada uma senhora dentro dos padrôes de comportamento, moradia e vestuário implícitos como textos culturais de grupos específicos. No processo de midiatização, podem ganhar relevo os traços do cômico e do bizarro, ou seja, a mídia pode vir a operar uma nova reconfiguração do funk, ao modo de paródia. Mas, em que se pese a açáo da mídia, o funk já foi transformado por 
MC Véia a partir de suas próprias referências. Ela transforma-se, no contato com o funk, e transforma-o, antropofagicamente. Se por um lado, nos conselhos que dá às mulheres em Concubina, reforça-se a ideia de mulher-objeto, que deve fazer os gostos de seu "machão" para não ser traída, o uso do humor autoriza um discurso que não se ressente do próprio fracasso e que reinventa a aventura de existir, apesar do abandono. Leda, ainda que abandonada e exilada, soube se adaptar e, agora, é famosa, está nas mídias e, nas redes sociais, ressalta o valor da fama e manda "beijo no ombro das inimigas", outra expressão bastante presente no universo do funk, que ganhou popularidade a partir da música "Beijinho no ombro" (2013), de Valesca Popozuda.

Quando canta, MC Véia transforma a estrutura musical do funk, imprimindo-lhe uma cadência mais lenta, com as letras bem pronunciadas e um ritmo que remete às marchinhas de carnaval e outros ritmos e referências, que podem ser associados ao repertório musical de Leda, já que revelou em entrevista para a $\mathrm{EGO}^{4}$ que adora Ângela Maria e Nelson Rodrigues, inclusive tendo cantado cançôes dos músicos aos 7 anos de idade, em um circo. Em seus clipes, ela adota as roupas típicas do universo funk, mas insere também elementos que mais se parecem com fantasias, como os óculos grandes e coloridos, mas também aparece vestida como uma senhora comum.

Ao traduzir os elementos do funk, MC Véia parece transformá-los por meio de um processo similar à paródia, que foi recorrentemente utilizada por Oswald de Andrade como uma das formas de tradução antropofágica:

\footnotetext{
$\mathrm{Na}$ paródia, elementos distantes aproximam-se, dispersam-se os antagonismos, convida-se o receptor à participação ativa no processo de reconhecimento / negação / valorização dos elementos incorporados. Reconhecidos os elementos originais da paródia, reconhecido o jogo de transmutação, produz-se o riso. (SILVA, 2007, p. 22).
}

Portanto, a partir de uma referência a um texto anterior, chega-se a um novo texto, no qual se destacam elementos que servirão para hiperbolizar o humor. Quando nos referimos a texto, trata-se do texto na concepção de Lotman (1978), ou seja, a de uma unidade da cultura, capaz de produzir sentidos. No caso de MC Véia, a mescla se faz entre os textos da música, da dança e do vestuário. São séries culturais que compóem o texto da cultura funk, alterada pela cultura de origem de Leda Maria.

Do funk carioca, restam elementos do ritmo (ainda que alterado), da dança, e do vestuário: o boné, as correntes grossas, as camisetas com inscriçóes em inglês. Ingressam elementos estranhos, tais como os coloridos e enormes óculos de carnaval, o canto articulado de Leda, sua maturidade. Somados, estes componentes operam uma provocação. Ao juntarem-se, as formas e linguagens aparentemente díspares promovem uma profanação tanto do funk quanto da própria Leda Maria, que se transforma de dona de casa em MC Véia. Retomam-se e transformam-se suas origens, ao devorar o funk com uma dose de humor, virando-o do avesso. 
Chamie afirma, sobre Oswald de Andrade:

A moral oswaldiana, portanto, é a moral do avesso, ou seja, da irreverência, da ironia, e da piada, armas de ataque contra a seriedade e seus modelos. Oswald parece ter entendido que a atitude séria está sempre do lado direito, e o lado direito, muitas vezes, é um mero fenômeno fruto de um consentimento sem razão (CHAMIE, 1976, p. 5).

Vale lembrar que entre as máximas colocadas por Oswald de Andrade em seu Manifesto Antropófago está a de que "a alegria é a prova dos nove". Seus personagens, a exemplo, o Serafim Ponte Grande, do "romance-invenção" de mesmo nome, caracterizam-se por serem hiperbolicamente caricatos, muitas vezes levados ao grotesco. Tal procedimento sugere uma opção crítica do autor e, mais do que isso, uma postura autocrítica. São personagens do cotidiano: sonhadores, amantes, aventureiros, mas também superficiais, hedonistas, interesseiros. Sáo comparsas de Oswald. São o próprio Oswald, pois que retratam a burguesia endinheirada e fútil com a qual convivia, da qual fazia parte e era um exemplar. A diferença está no fato de que o poeta soube não se levar a sério, tampouco acreditou na classe à qual pertencia, o que lhe rendeu desencantos e desafetos: "Como tinha a irresistível vocação de debochar das vetustas e autoritárias instituiçóes do patriarcado brasileiro, Oswald acabou confinado num picadeiro" (CARNEIRO, 1995, p. 61).

Assim, talvez também se possa reconhecer em MC Véia, para além de uma caricatura de Leda ou do funk, para além do cômico explorado pelas mídias, aspectos críticos de um existir no qual o imprevisível é a tônica. Para este imprevisível, converge uma utopia da tolerância, apreendida na visão antropofágica:

Tolerar é definir o ponto até onde se pode ir, é aceitar sabendo, e acatar e ser crítico ao mesmo tempo. Tolerar é pesar, é "delimitar o círculo do seu horizonte", ainda com Nietzsche, é não permitir que o egoísmo impeça que o olhar se articule "ao horizonte de outrem". Para assim não se morrer "por moleza ou pressa excessiva". Tolerar, e é Silviano 5 quem traz esse vocabulário para nós, estudiosos de hoje, implica "a serenidade, a boa consciência, a alegria na ação, a confiança no futuro". Tolerar é saber pesar. Ou, com Nietsche também, "demarcar entre o que é claro e pode abarcar-se com o olhar e o que é obscuro e confuso". Para, assim, podermos "esquecer a tempo"; "recordar a tempo" (SANTOS, 1995, p. 104).

E se a consciência de que tudo é incerto vai de par com a necessidade de se compreender a diferença, só resta rir de quem pensamos que somos

\section{Considerações Finais}

É certo que a visão antropofágica de Oswald de Andrade, como bem analisa Lima (1995), comporta uma utopia, com aspectos equivocados, tais como a libertação do homem pela técnica, quando o ócio reinaria no Matriarcado de Pindorama. E Lima ainda pondera (1995, p. 97): "A cotação da utopia está em baixa, o horizonte utópico e, portanto, os planos de uma sociedade mais justa num mundo mais humanizado estão fora de moda”. 
Em que se pesem os equívocos apontados por Lima (idem), o crítico louva o fato de que Oswald de Andrade tenha trazido a utopia para o centro de sua discussão. Mais do que isto, acrescentamos, a manutençáo de uma utopia talvez seja o maior acerto do poeta.

Pensando nesta utopia, concluímos que a personagem de MC Véia pode oferecer a leitura de muitos processos de alteridade, a começar daquele que coloca em jogo duas personagens: Leda, a senhora, dona de casa, cuja jornada heroica consiste em múltiplos deslocamentos e adaptaçóes territoriais e de cultura. A trama de Leda envolve o chamado para o amor, o abandono do lugar de origem para seguir o outro, o marido, em seguida, a mudança de casa, de cultura e de vida, traiçóes que resultam nas perdas do afeto e da identidade e na necessidade de um novo deslocamento, para um ponto mais distante e mais desconhecido. É esta personagem que contracena com MC Véia, a mulher reinventada no contato com o diverso que construirá uma outra narrativa, na qual se destacam os aspectos positivos dessa experiência de fracasso, amoroso e financeiro, em uma abordagem cuja tônica é o humor, capaz de mostrar o avesso das coisas, invertendo valores e escancarando o absurdo da condição humana, com todas as suas incertezas.

Neste processo, carregado de tensôes, não é possível saber até que ponto Leda "favelou", ou em que medida foi o funk que sofreu a ação de Leda, agora MC Véia. E também não se pode estabelecer os limites entre a midiatização do funk e a favelização da mídia. Ocorre, sim, uma possibilidade dialógica e polissêmica de se compreender o funk e seu universo, longe dos preconceitos e juízos de valor e de gosto, a partir de uma visada mais complexa, não excludente, em que o trânsito entre as diferenças persiste ante as tensóes que se apresentam no contato com o outro 


\section{Referências Bibliográficas}

ANDRADE, Oswald de. A utopia antropofágica. Sáo Paulo: Globo, 1990.

BARREIROS, Renato. Ostentação em crise. Disponível em: <http://farofafa.cartacapital.com.br/2014/08/21/ostentacao-em-crise/>. Acesso em 02 de set. de 2014.

BRISOLLA, Fábio. Carioca de 67 anos conhece o funk e vira MC Véia. .http://www1.folha.uol.com.br/cotidiano/2014/08/1504650-mc-veia. shtml>. Acesso em 04 de set. de 2014.

BUENO, André. A felicidade guerreira - Oswald de Andrade e as utopias. In: TELES, Gilberto Mendonça. Oswald Plural. Rio de Janeiro: Ed. Da UERJ, 1995.

CANCLINI, Néstor García. Culturas Hibridas. São Paulo, SP: Editora da Universidade de São Paulo, 2008.

CARNEIRO, Geraldo. A influência da obra oswaldiana na poesia dos anos 70 e no tropicalismo. In: TELES, Gilberto Mendonça. Oswald Plural. Rio de Janeiro: Ed. Da UERJ, 1995.

CHAMIE, Mário. A linguagem virtual. São Paulo: Quíron, Conselho Estadual de Cultura, 1976.

COUlON, Alain. A escola de Chicago. Campinas, SP: Papirus, 1995.

CUNHA, Eneida Leal. A antropofagia, antes e depois de Oswald. In: TELES, Gilberto Mendonça. Oswald Plural. Rio de Janeiro: Ed. Da UERJ, 1995.

FIGUEIREDO, Vera Lúcia Follain. Oswald de Andrade e a descoberta do Brasil. In: TELES, Gilberto Mendonça. Oswald Plural. Rio de Janeiro: Ed. Da UERJ, 1995.

G1. MC Britney e MC Rianna fazem sucesso no funk usando nomes de cantoras pop.Disponível em: <http://extra.globo.com/tv-e-lazer/musica/ mc-britney-mc-rianna-fazem-sucesso-no-funk-usando-nomes-de-cantoras-pop-12185573.html\#ixzz3CBQI1iy6>. Acesso em 02 de set. 2014.

HERSCHMANN, Micael. O funk e o Hip Hop invadem a cena. Rio de Janeiro: UFRJ, 2000.

LIMA, Luiz Carlos. Oswald de Andrade - a utopia antropofágica: uma utopia sem história. In: TELES, Gilberto Mendonça. Oswald Plural. Rio de Janeiro: Ed. Da UERJ, 1995.

LOTMAN, Iuri. A estrutura do texto artístico. Lisboa: Estampa, 1978.

MARQUES, Carol. Aos 67 anos, MC Véia é a nova sensação do funk: 'Era meu sonho'. Disponível em: <http://ego.globo.com/famosos/noticia/2014/08/aos-67-anos-mc-veia-e-nova-sensacao-do-funk-era-meu-sonho.html>. Acesso em 02 de set. de 2014.

MARTÍN-BARBERO, Jesús. Dos meios às mediaçôes: comunicação, 
cultura e hegemonia. Rio de Janeiro: UFRJ, 1997.

SANTOS, Roberto Corrêa dos. O político e o psicológico, estágios da cultura. In: TELES, Gilberto Mendonça. Oswald Plural. Rio de Janeiro: Ed. Da UERJ, 1995.

SEPÚLVEDA, Carlos. Oswald de Andrade e o paradigma perdido. In: TELES, Gilberto Mendonça. Oswald Plural. Rio de Janeiro: Ed. Da UERJ, 1995.

SILVA, Míriam Cristina Carlos Silva. Comunicação e cultura antropofágicas: Midia, corpo e paisagem na erótico-poética oswaldiana. Porto Alegre: Sulina; Sorocaba: Eduniso, 2007.

\section{NOTAS}

(1) Hip Hop é um movimento que envolve elementos culturais tais como o DJ, Grafite, Rap e Break, entre outros.

(2) A raiz do Hip Hop provém da Jamaica. Richard (2005) ressalta que desde a década de 1960, a população carente jamaicana passou a utilizar a música como meio de expressão contra o sistema local. Essa música é composta pelos toastes - responsáveis pelos discursos - e pelo acompanhamento do sound systems, aparelhos de reproduçáo de áudio, caracterizados pela potência das caixas de som.

(3) Página do Facebook MC Véia: Disponível em <https://www.facebook.com/ mcveiaoficial?fref=ts>. Acesso em 07 de out. de 2014.

(4) Aos 67 anos, MC Véia é a nova sensação do funk: 'Era meu sonho'. Disponível em: <http://ego.globo.com/famosos/noticia/2014/08/aos-67-anos-mc-veia-e-nova-sensacao-do-funk-era-meu-sonho.html>. Acesso em 07 de out. 2014.

(5) Santos se refere a Silviano Santiago, no ensaio "Oswald de Andrade ou: o elogio da tolerância racial”, publicado em Ideias - Ensaios, no Jornal do Brasil, em 9 de setembro de 1990. 